\title{
Dolor en la enfermedad de Parkinson. Una mirada a un aspecto poco conocido de esta patología
}

\author{
J. Rotondo¹, M. Toro¹, M. Bolívari,2, M. E. Seijas y C. Carrillo \\ ${ }^{1}$ Anestesiólogo. Medicina Intervencionista del Dolor. ${ }^{2}$ Unidad de Medicina del Dolor (UMD) del Instituto \\ Médico la Floresta. Caracas. Venezuela. Expresidente AVED.
}

\section{ABSTRACT}

Parkinson's disease (PD) is a neurodegenerative disease, the second most prevalent, after Alzheimer's disease. It presents both motor and non-motor symptoms; These include autonomic dysfunction, unexplained pain, cognitive impairment, anxiety, depression, among others. Some of these patients experience pain as an early symptom of Parkinson's, even before the expression of their disease. Among people who have PD and who experience pain, they describe it as a worrisome symptom, being a cause of suffering and disability. However, despite this, pain in PD often remains undiagnosed and untreated. Therefore, it is important to understand that pain can be part of the Parkinson's experience and learn ways to manage it.

This paper reviews current data on possible mechanisms, classifications, evolution, potential risk factors and pain control in PD. The mechanism of pain in this situation is complex, and is influenced by different factors, which may be linked to pathological changes in the anatomical structures involved in nociceptive mechanisms.

Key words: Pain, Parkinson's disease, dystonia, akathisia, dopamine.

\section{RESUMEN}

La enfermedad de Parkinson (EP) es una enfermedad neurodegenerativa, la segunda con mayor prevalencia después de la enfermedad de Alzheimer. Presenta tanto síntomas motores como no motores; entre estos últimos se encuentran disfunción autonómica, dolor inexplicable, deterioro cognitivo, ansiedad, depresión, entre otros. Algunos de estos pacientes experimentan el dolor como un síntoma temprano de Parkinson, incluso antes de la expresión de su enfermedad. Entre las personas que tienen EP y que experimentan dolor, lo describen como un síntoma preocupante, siendo una causa de sufrimiento y de incapacidad. Sin embargo, a pesar de ello, el dolor en la EP a menudo permanece sin diagnóstico y sin tratamiento. Por tanto, es importante entender que el dolor puede ser parte de la experiencia del Parkinson y aprender las formas de manejarlo.

Este trabajo revisa datos actuales sobre posibles mecanismos, clasificaciones, evolución, factores de riesgo potenciales y control del dolor en la EP. El mecanismo del dolor en esta situación es complejo, y está influenciado por distintos factores, pudiendo estar vinculado a cambios patológicos en las estructuras anatómicas involucradas en mecanismos nociceptivos.

Palabras clave: Dolor, enfermedad de Parkinson, distonía, acatisia, dopamina.

\section{INTRODUCCIÓN}

La enfermedad de Parkinson (EP) se presenta como una patología crónica, de larga duración, irreversible y con una sintomatología que empeora con el tiempo. Constituye la segunda enfermedad neurodegenerativa más frecuente, después de la enfermedad de Alzhei- mer. En países como los Estados Unidos se estima una prevalencia de 350 por 100.000 habitantes; es más frecuente en el sexo masculino con el doble de frecuencia, aproximadamente, con respecto al femenino $(1,2)$.

La EP fue descrita por primera vez en 1817 por el neurólogo británico James Parkinson, quien inicialmente la denominó "alteración del sistema motor" (3). 
Actualmente se define como una afección neurodegenerativa progresiva que surge como consecuencia de una alteración en la producción de dopamina por parte de las neuronas dopaminérgicas de la substantia nigra, que causa un desequilibrio en el control extrapiramidal del sistema motor; se le incluye dentro de los trastornos de movimiento $[4,5)$.

La sintomatología suele presentarse después de los 60 años y es muy poco común antes de los 30 años de edad, aunque existe una minoría de pacientes con inicio precoz o juvenil $(6,7)$. La prevalencia va desde el $1 \%$ en la población alrededor de los 65 años, hasta el $5 \%$ a los 85 años de edad (8). Después de los 90 años es poco frecuente el inicio de la enfermedad $(2,9)$.

A pesar de los esfuerzos investigativos, aún se desconocen las causas que desencadenan esta enfermedad. En la patogenia de EP se proponen varios mecanismos como causantes de la lesión del grupo de neuronas presentes en la substantia nigra, sin que exista hasta el momento una causa directamente relacionada. Entre estos mecanismos se postula una combinación de predisposición genética junto a factores ambientales $(4,5,9,10)$. El factor genético, que inicialmente se propuso como única causa, se ve más asociado con la forma atípica de inicio temprano de la EP que representa una minoría de los casos $(1,6)$, lo cual apoya la teoría de que más de un factor (además del genético) puede ser la causa de esta patología $(9,11)$. Se ha demostrado con la identificación de, al menos, nueve loci y la clonación de genes involucrados en la forma familiar [11].

Entre los factores ambientales propuestos están la oxidación desencadenada por la presencia de radicales libres (Tabla I), la acción de toxinas exógenas como el manganeso y los plaguicidas organofosforados, también se han considerado factores ambientales aún desconocidos $[7,9)$; así, la exposición aguda a la 1-metil4-fenil-1, 2, 3,6 tetrahidropiridina, un tóxico análogo a la meperidina que comúnmente se encuentra como contaminante en psicoestimulantes ilícitos, es una cau-

TABLA I

HALLAZGOS INDICATIVOS DE ESTRÉS OXIDATIVO EN LA ENFERMEDAD DE PARKINSON

\begin{tabular}{|l} 
Marcadores de estrés oxidativo \\
\hline - Disminución de glutatión reducido en la sustancia \\
negra \\
- Aumento de hierro en la sustancia negra \\
- Disminución de la enzima glutatión peroxidasa \\
- Aumento de la actividad de la enzima de la super \\
óxido dismutasa \\
- Aumento de los productos derivados \\
de la peroxidación lipídica (por ejemplo \\
malonildialdehido) \\
- Aumento de ácidos grasos polinsaturados en la \\
sustancia negra \\
- Alteración de la enzima alfa cetoglutarato \\
deshidrogenasa mitocondrial
\end{tabular}

sa conocida de desarrollo rápido de la enfermedad y se ha utilizado para crear modelos experimentales para su estudio.

Esta enfermedad neurodegenerativa se caracteriza por la presencia de temblor en reposo, bradicinesia o hipocinesia, marcha inestable y rigidez muscular, junto a otras manifestaciones como son la alteración de los reflejos posturales, la postura en flexión y el fenómeno de congelación. Para diagnosticar la enfermedad, un paciente necesita presentar, al menos, dos de los síntomas citados anteriormente, siendo imprescindible la presencia de temblor o la bradicinesia. Otros hallazgos frecuentes son dolor inexplicable, estreñimiento, retención urinaria, disfunción sexual, demencia, depresión, patrones de sueño alterados o pérdida de peso $(9,12,13)$. Pueden detectarse años antes de la aparición de cualquiera de los signos motores cardinales (14). Un estudio destacado mostró que prácticamente todos los pacientes de EP informan al menos de un síntoma no motriz (SNM) cuando estas manifestaciones son activamente investigadas usando cuestionarios específicos, alcanzando un promedio de ocho síntomas diferentes por paciente. En este mismo estudio, los SNM más frecuentes fueron neuropsiquiátricos, gastrointestinales y síntomas relacionados con el dolor (15). Otros refieren que, en las primeras etapas de la enfermedad, los SNM más comunes son la hiposmia, el dolor y los trastornos del sueño (16).

Aunque el dolor nunca ha sido considerado un síntoma primario de la EP, varios investigadores, incluyendo Charcot (17), ya se habían referido a aspectos dolorosos de la enfermedad: "A veces el párkinson va precedido por dolores neurálgicos o reumatoides, que ocasionalmente son de gran intensidad, localizándose en la extremidad (...) que pronto será afectada (...) por la agitación convulsiva".

\section{CONSIDERACIONES NEUROANATÓMICAS Y NEUROFISIOLÓGICAS DE LA ENFERMEDAD DE PARKINSON. ESQUEMA NEUROQUÍMICO DEL CIRCUITO DE LOS GANGLIOS BASALES}

Normalmente existe un equilibrio entre la actividad contráctil causada por la acetilcolina y la actividad inhibitoria mediada por la dopamina, lo cual permite un tono y una función muscular adecuada. Existen cinco tipos de receptores dopaminérgicos: D1, D2, D3, D4 y D5. Los tipos D1 y D5 son excitatorios, mientras que el resto son inhibitorios, lo cual hace que el efecto neto de la dopamina sea la inhibición de la acción celular. Al unirse a su receptor, la dopamina activa la proteína $G$ unida a este. Esto hace que las subunidades alfa se separen del resto de la proteína y se active la adenilciclasa que logra aumentar los niveles de AMP cíclico. Finalmente, se produce un efecto inhibitorio sobre la acción de la célula que, en el caso de la célula muscular, sería inhibición de la contracción. En la EP se altera la producción de dopamina, y prevalece el efecto contráctil de la acetilcolina, cuya concentración estriatal se mantiene normal (18).

Ahora bien, en un individuo sano, la generación de los movimientos motores coordinados por parte del cerebro radica en un equilibrio entre la activación de los movimientos voluntarios o vía directa y la acción de 
la vía inhibitoria o vía indirecta. En ambas vías participa el neurotransmisor dopamina, así como sus receptores. Así, en condiciones normales, están implicados los receptores tipo 1 de dopamina (D1), situados en el globo pálido interno y en la parte reticular de la sustancia negra, y también participan neuronas dopaminérgicas que proyectan al globo pálido externo, representados por los receptores D2. En los pacientes con EP, debido a la presencia de una degeneración dopaminérgica, estas vías se encuentran afectadas, produciéndose una hipoactividad en la vía directa y una hiperactivadad en la vía inhibitoria.

El estriado dorsal (caudado-putamen) recibe estímulos excitatorios, glutamatérgicos, de las áreas corticales motoras. El feedback último del estriado dorsal a la corteza lo lleva a cabo el tálamo motor y se dirige directamente a la corteza motora, donde se encuentran las áreas implicadas en la organización del movimiento. Más del $90 \%$ de las neuronas del estriado son neuronas GABAérgicas de mediano tamaño que proyectan fuera del estriado. Un modelo simplificado del funcionamiento de los ganglios basales comprende dos circuitos ya mencionados: uno Directo y otro Indirecto (Figura 1). Las neuronas glutamatérgicas de la corteza motora inervan dos tipos principales de neuronas GABAérgicas del estriado. Un tipo de neuronas coexpresa los neuropéptidos dinorfina (dyn] y sustancia $P$ (SP) y posee receptores dopaminérgicos D1. Estas neuronas proyectan directamente al globo pálido parte interna (GPi) y a la sustancia negra (compacta y reticulata), con una acción inhibitoria sobre ambas (vía directa). El otro tipo de neuronas GABAérgicas expresa encefalina (enk) y receptores dopaminérgicos D2. Estas neuronas proyectan indirectamente al GPi y sustancia negra (SN) a través del globo pálido parte externa (GPe) y el núcleo subtalámico (NST). En primer lugar, envían estímulos inhibitorios al GPe, que a su vez ejerce efecto inhibitorio (acción GABA) sobre el NST. Este último ejerce efecto excitatorio glutamatérgico sobre el GPe, GPi y SN (vía indirecta). Las neuronas dopaminérgicas de la sustancia negra pars compacta [SNc] modulan los impulsos estriatales. Parece ser que ejercen efecto excitatorio sobre las neuronas GABAérgicas estriatales con receptores D1 y efecto inhibitorio sobre las neuronas GABAérgicas con receptores D2. La actividad de estas neuronas dopaminérgicas está controlada por las proyecciones GABAérgicas desde el estriado y por las proyecciones glutamatérgicas del núcleo subtalámico (NST). La principal vía de salida de los ganglios basales tiene lugar desde neuronas GABAérgicas del GPi, que proyectan al tálamo motor. El modelo mencionado es simplificado, y no explica el papel de un porcentaje (10\%) de neuronas GABAérgicas del estriado que expresan tanto receptores $\mathrm{D} 1$ como D2, así como el papel de las interneuronas colinérgicas del estriado, que expresan también somatostatina $(19,20)$.

\section{FISIOPATOLOGÍA DE LA ENFERMEDAD DE PARKINSON}

La EP se caracteriza por la pérdida progresiva de neuronas dopaminérgicas en determinadas regiones del sistema nervioso central, como en la región pars compacta de la sustancia negra, el locus coeruleus y núcleos del rafe y neuronas del bulbo olfatorio; también

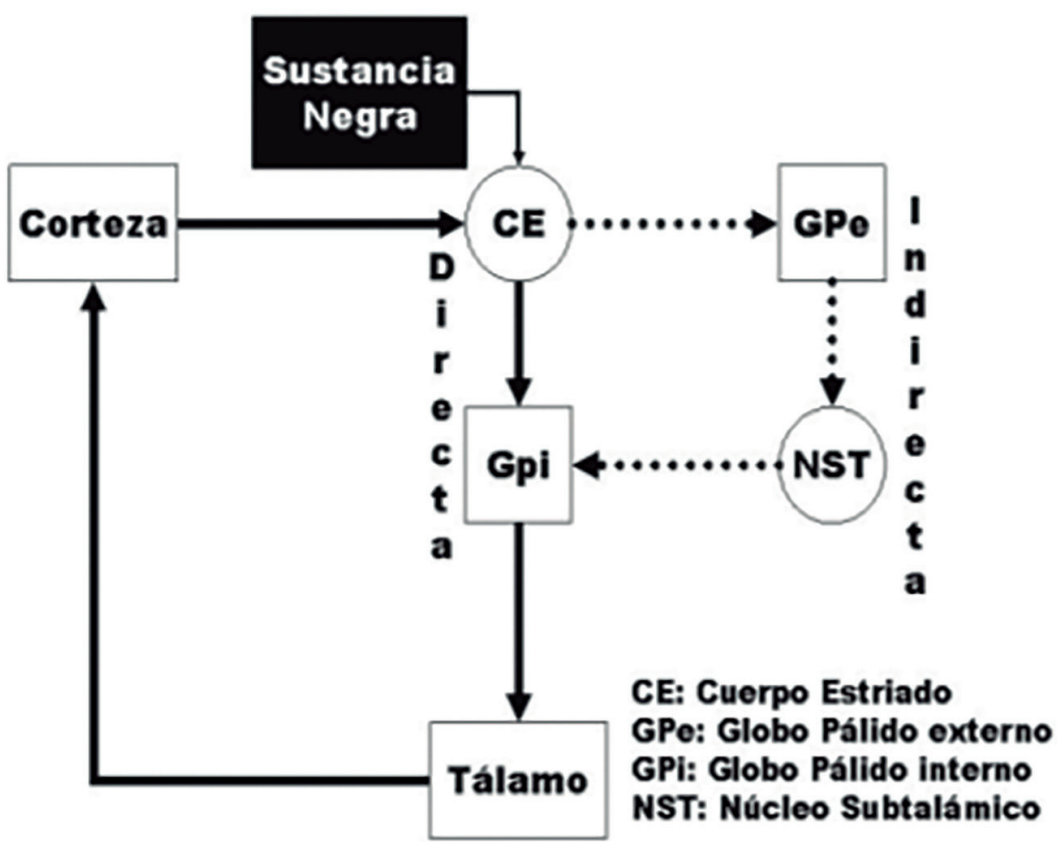

Fig. 1. Vías directa e indirecta de las conexiones del núcleo de entrada y de salida. 
se encuentran afectadas las neuronas colinérgicas, catecolaminérgicas y serotoninérgicas.

Todo ello conlleva a una incapacidad para la realización de los movimientos coordinados. La pérdida de comunicación dopaminérgica entre los ganglios basales y el cuerpo estriado va a generar una serie de acontecimientos causantes de la sintomatología clásica en pacientes con párkinson.

La muerte de neuronas dopaminérgicas en la pars compacta de la sustancia negra conlleva a la pérdida de dopamina en el núcleo caudado y putamen. Las manifestaciones patológicas incluyen cambios degenerativos, tales como la muerte neuronal, la depigmentación en la sustancia negra y la aparición de inclusiones intracelulares en las neuronas dopaminérgicas denominadas cuerpos de Lewy (ver más adelante). Los efectos funcionales de la pérdida de dopamina en los pacientes con párkinson pueden ser entendidos según el mecanismo comentado del circuito de los ganglios basales (Figuras 1 y 2). Normalmente, la dopamina ejerce un efecto inhibitorio sobre las neuronas GABAérgicas del estriado con receptores D2 (vía indirecta) y un efecto excitatorio en las neuronas con receptores D1 (vía directa). Al disminuir el efecto inhibitorio sobre neuronas con receptores $\mathrm{D} 2$, aumenta la acción inhibitoria GABAérgica del estriado sobre el GPe, frenando la acción inhibitoria del GPe sobre el NST. Se produce así una liberación del NST al desaparecer dicho freno, con lo que aumenta el estímulo excitatorio de dicho núcleo a todos los niveles: SN, GPe y GPi. Por otro lado, la disminución de la acción dopaminérgica sobre neuronas con receptores D1 estriatales conlleva una amortiguación de la acción inhibitoria GABAérgica de las neuronas estriatales sobre el GPi. Por lo tanto, como resultado final, en ambas vías, directa e indirecta, se produce un incremento de la acción GABAérgica del GPi. Esta hiperactividad causa la inhibición del tálamo motor que es el responsable del control motor de las áreas corticales implicadas en la iniciación de los movimientos. La hipoactividad glutamatérgica tálamocortical se relaciona con síntomas como la rigidez, la lentitud de movimientos, la acinesia, etc. El temblor se cree debido al "escape" del tálamo motor a la potente inhibición procedente del GPi, originando ráfagas de disparo (cada 125-250 ms) hacia la corteza que son causantes del temblor muscular (4-8 veces por segundo (21).

La aparición de los síntomas parkinsonianos no ocurre hasta que se ha perdido un $80 \%$ de las neuronas en la SN aproximadamente (el conteo celular no supera las 100 mil) (22). El resto de las neuronas no afectadas presentan mecanismos de plasticidad neuronal, produciendo un aumento en la cantidad de dopamina, así como el desarrollo de hipersensibilidad de receptores dopaminérgicos. La reserva funcional a través de estas adaptaciones explica la progresión de la EP, retrasando la aparición de los síntomas de la enfermedad. Las lesiones de evolución rápida, tales como las producidas por neurotoxinas, también producen síntomas parkinsonianos. Se ha postulado que algún insulto de tipo tóxico
Normal

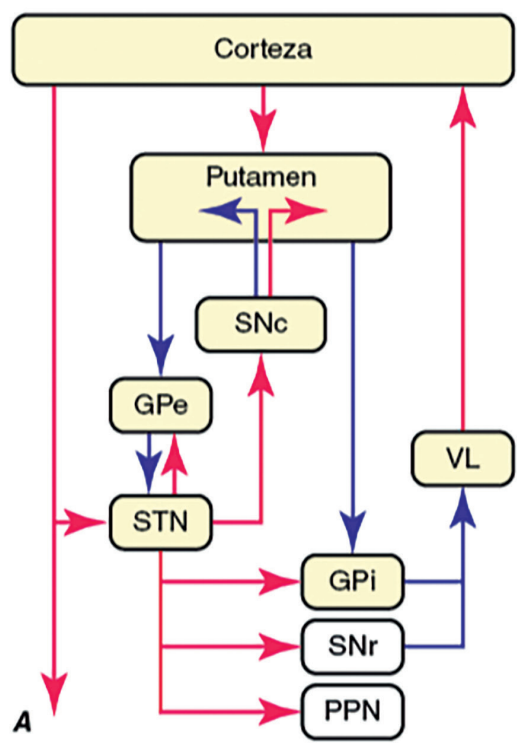

PD

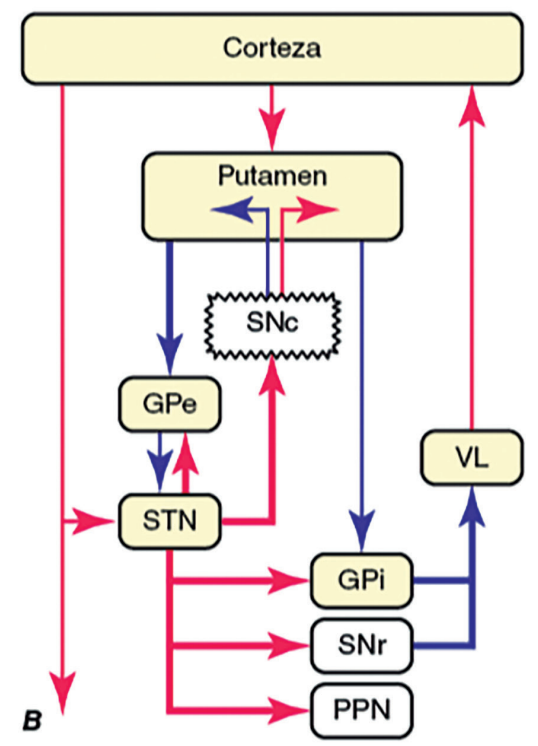

VL: núcleo ventral lateral del tálamo. VA: núcleo ventral anterior del tálamo. GPe: globo pálido externo. NST: núcleo subtalámico. SNc: sustancia negra compacta. GPm: globo pálido medio. GPi: globo pálido interno.

Fuente: Longo DL, Fauci AS, Kasper DL, Hauser SL, Jameson JL, Loscalzo J. Harrison. Principios de Medicina Interna. $18 .{ }^{a}$ edición.

Fig. 2. Modelo de funcionamiento de circuito motor de los ganglios basales. A. Condición normal. B. Enfermedad de Parkinson. 
o vírico podría acelerar la degeneración progresiva neuronal. Los estudios anatomopatológicos de cerebros de pacientes post mortem que han padecido EP revela la presencia, ya mencionada, de unas inclusiones eosinofílicas, denominadas cuerpos de Lewy, que contienen proteínas como la ubiquitina y la alfa sinucleína. Esta última participa en el reciclaje de vesículas sinápticas $(23,24)$. Estas proteínas se acumulan formando "agresomas", los cuales promueven el estrés oxidativo y la apoptosis. Estos agregados no son exclusivos de la EP y pueden observarse en pacientes con enfermedad de Alzheimer, síndrome de Hallervorden-Spatz e, incluso, en sujetos sin enfermedad neurológica (10).

La histopatología revela la presencia de neuritas distróficas en todo el sistema nervioso central, además de una pérdida variable de neuronas en núcleos subcorticales, en particular de la parte compacta de la sustancia negra, el locus coeruleus, y el núcleo basal de Meynert y el núcleo dorsal motor del nervio vago. Adicionalmente, hay una depleción intensa de neuronas melanizadas (45-66\%), así como de neuronas dopaminérgicas inmunorreactivas para la tirosina hidroxilasa (60-88 \%) de la parte compacta de la sustancia negra, en particular en el tercio ventrolateral (91-97\%), que se proyecta al estriado, seguido de las áreas medioventral, dorsal y lateral (25).

\section{FACTORES AMBIENTALES. PAPEL DEL ESTRÉS OXIDATIVO}

Aunque no existen pruebas directas, distintos hallazgos en humanos y animales de experimentación apoyan la hipótesis de que el estrés oxidativo es el responsable de la muerte de células dopaminérgicas en la EP (Tabla I).

Las neuronas dopaminérgicas de la sustancia negra son más dependientes del metabolismo energético y la fosforilación oxidativa mitocondrial que otras poblaciones del tronco encefálico (por lo que son más sensibles al estrés oxidativo); además presentan bajos niveles de proteínas de unión al calcio, lo que implica disminución de la función neuroprotectora.

Según lo descrito, el estrés oxidativo es la "fuerza motriz" de la neurodegeneración y su causa es desconocida (26). Las pruebas sugieren que, en aquellas situaciones donde la defensa celular antioxidante no consigue compensar el incremento de especies reactivas de oxígeno (ERO), constituiría la antesala de la muerte celular.

Una de las posibles explicaciones se encuentra en que en el interior de las citadas neuronas de pacientes de EP se ha observado un aumento en la acumulación del catión hierro. Los niveles de hierro están incrementados un $129 \%(27,28)$, y los del péptido antioxidante glutatión están disminuidos un $40 \%$ (29), lo cual podría facilitar la aparición de reacciones con la formación de radicales fuertemente oxidantes, como ion superóxido. La enzima sintetasa de óxido nítrico también está aumentada en la glía de la sustancia negra (30), lo que lleva a la formación de peroxinitritos y radicales hidroxilo, altamente oxidantes. La formación excesiva de especies reactivas de oxígeno y de nitrógeno conlleva daño en proteínas, lípidos, ADN y ARN. Los niveles de carbonilos de proteínas, marcadores de oxidación pro- teica, están dos veces elevados en la sustancia negra de enfermos de EP [31). Los niveles de hidroperóxidos lipídicos, indicadores de oxidación lipídica, están diez veces aumentados (32). Finalmente, la 8-hidroxiguanina, indicador de daño oxidativo en el ARN y ADN, está también aumentada (33). Además del estrés oxidativo, existe un ciclo tóxico neurodegenerativo caracterizado por disfunción mitocondrial, excitoxicidad mediada por glutamato e inflamación en la sustancia negra. Todo esto explica la rápida progresión de la EP una vez que la sintomatología se manifiesta.

Debido a que la dopamina participa como neurotransmisor a nivel sistémico en otras funciones del organismo, una disminución en sus niveles puede asociarse con otras alteraciones clínicas que afectan, por ejemplo, a la presión sanguínea y la contracción cardiaca o a la regulación hormonal de la prolactina. Por ello, en pacientes con EP pueden aparecer acontecimientos adicionales, como hipoventilación central, una marcada hipotensión ortostática, mioclonía o incontinencia urinaria [26].

\section{DOLOR EN LA EP. IMPORTANCIA DEL PROBLEMA}

El interés por el estudio de los síntomas motores en la EP (Tabla II) históricamente ha sido mayor que el manifestado por la valoración de los síntomas no motores (Tabla III). Pacientes con EP pueden presentarse con dolor severo o intratable, el cual puede ser más intenso que los síntomas motores, pero aun así sigue siendo un síntoma subvalorado, esto a pesar de que la correlación entre dolor y EP fue descrita por James

TABLA II

ENFERMEDAD DE PARKINSON. SIINTOMAS MOTORES MÁS FRECUENTES

\begin{tabular}{|l|l|}
\hline \multicolumn{2}{|c|}{ Síntomas motores } \\
\hline - Temblor de manos & - Calambres musculares \\
- Dificultad para & - Dificultad para usar las \\
$\quad$ levantarse de la silla & manos \\
- Dificultad para hablar & - Rigidez general \\
- Lentitud general & - Problemas de equilibrio \\
\hline
\end{tabular}

TABLA III

ENFERMEDAD DE PARKINSON. SÍNTOMAS NO MOTORES

\begin{tabular}{|l|l|}
\hline \multicolumn{2}{|c|}{ Síntomas no motores } \\
\hline - Dolor & - Ansiedad \\
- Intranquilidad & - Crisis de angustia \\
- Dificultad para respirar & - Insomnio o trastornos \\
- Sudoración excesiva & de sueño \\
- Dificultad para pensar & - Lentitud del \\
con claridad & pensamiento \\
\hline
\end{tabular}


Parkinson como un "dolor reumático que extiende desde los brazos a los dedos" (34).

Aunque algunas investigaciones conceden importancia gradual a los síntomas no motores (SNM), solo una minoría de los estudios se han enfocado en la experiencia dolorosa que sufren los pacientes con EP.

Se requiere habilidad para diagnosticar y experiencia clínica para determinar la causa del dolor. La herramienta de diagnóstico más importante es la historia clínica del paciente.

Quizás la tarea más determinante para las personas con párkinson que experimentan dolor es describir con la mayor precisión que puedan si los medicamentos inducen, agravan o alivian su dolor. Más de la mitad de las personas con párkinson dicen haber sentido síntomas dolorosos, rigidez, entumecimiento y hormigueo en el algún punto del curso de su enfermedad. El dolor en la EP es un síntoma temprano y puede preceder a los síntomas motores por varios años $(14,35,36)$.

La prevalencia del dolor en la EP puede variar de $34 \%$ (37) al $83 \%$ (38), dependiendo de las evaluaciones metodológicas.

Por otro lado, el dolor de los pacientes con párkinson ocurre dos o tres veces más frecuentemente que en los individuos de edad similar sin EP (38-40).

El dolor no parece estar influido por el sexo, edad o variables geográficas / culturales [41].

El dolor generalmente ocurre en el lado en el que aparecen los síntomas motores o son más graves (42). Sin embargo, esto no siempre es el caso, pues algunos pacientes pueden presentan dolor en el lado no afectado por la enfermedad (43).

En términos de localización del dolor, aunque puede ser bastante variable, la parte inferior de la espalda y las piernas son las regiones más afectadas (41). El dolor en el hombro, comúnmente informado por los pacientes de EP $(15,43)$, puede ser el primer síntoma en $2-8 \%$ e incluso podría preceder a la aparición de los síntomas motores (44).

Se piensa que el dolor proviene de dos mecanismos diferentes: uno directamente relacionado con el síntoma neurológico (pseudoreumático y dopamínico sensible), y el otro se cree que se asocia con lesiones degenerativas que pueden empeorar con la progresión de la EP.

Las personas con dolor y EP tienen puntuaciones más altas en las escalas de evaluación de la depresión (45). Por ello, es importante que en cualquier evaluación del dolor de un individuo con EP se tenga en cuenta la posibilidad de la contribución de la depresión, la cual podría requerir tratamiento.

Otro elemento a tener en cuenta son los trastornos cognitivos, los cuales pueden influir en la percepción de dolor que siente el paciente.

Las enfermedades sistémicas, como la diabetes mellitus, la osteoporosis y las enfermedades reumáticas, también se asocian con una mayor prevalencia de dolor en la EP (46). Por último, también hay evidencia de una asociación entre los factores genéticos y dolor musculoesquelético; por ejemplo, las mutaciones en los genes SCN9A (canal de sodio Nav1.7) y FAAJ (amida hidrolasa de ácidos grasos, una enzima metabolizadora de cannabinoides] se han asociado con una mayor susceptibilidad a este síntoma en la EP (47).

\section{VALORACIÓN Y DIAGNÓSTICO DE DOLOR EN EL PACIENTE CON EP}

Existen una gran variabilidad en cuanto a las características de dolor en la EP, que puede ser de leve a severa intensidad, y de componentes nociceptivo y/o neuropático.

Lee y cols. evidenciaron que el $41,5 \%$ de los pacientes de su serie con dolor y EP no recibían tratamiento analgésico alguno (48-50).

Entre las herramientas diagnósticas para la evaluación del dolor en la EP, las más utilizadas son: Brief Pain Inventory $[36,38,51-56)$ y el SF 36 (49,57). También es de gran utilidad el cuestionario de dolor de McGil (38,58-60). De manera más específica, el dolor de la EP puede valorarse a través del Estudio DoPaMiP [Douleur et maladie de Parkinson en Midi-Pyrénées], que sugiere que se puede hacer distinción inicial entre el dolor relacionado con la EP (PRPD) y el dolor no relacionado con la EP (PUPD) (38).

"La escala del dolor de la enfermedad de Parkinson de King", que fue propuesta por un grupo multicéntrico del King's College Hospital en Londres, es oficialmente defendida por el "International Parkinson and Movement Disorder Society Non-Motor PD Study Group" para evaluar el dolor en la EP. Es un cuestionario con catorce preguntas que abarca siete dominios: 1) dolor musculoesquelético; 2) dolor crónico; 3] dolor relacionado con la fluctuación; 4] dolor nocturno; 5) dolor orofacial; 6] decoloración y edema/hinchazón; y 7) dolor radicular (61). Este es un nuevo enfoque para el dolor en la EP, lo que permitirá más pruebas en profundidad en ensayos clínicos para los tratamientos de este aspecto de la EP.

Como se ha referido, el dolor puede ser el primer síntoma de la enfermedad o presentarse en estadios avanzados $[62,63)$. Las dos claves que ayudan a reconocer que un dolor está relacionado con la propia EP son: su presentación o su máxima intensidad en el lado más afectado por el párkinson y que mejore tras la administración de medicación dopaminérgica. Lo característico es que el dolor se presente en periodos "off" y mejore durante los periodos "on" (64); desde luego, siempre hay que realizar una exploración general y neurológica minuciosa para descartar otras patologías.

La necesidad o no de solicitar pruebas complementarias para determinar el origen del dolor debe individualizarse en relación con los datos obtenidos en la anamnesis y en la exploración física de los pacientes. Si el dolor es lumbar e irradia a las piernas, en la exploración se objetivan alteraciones de la sensibilidad, fuerza o reflejos, habría que descartar la presencia de hernias discales o estenosis de canal lumbar, tan frecuente en este grupo de edad. Otras veces, el dolor se localiza en las articulaciones, y si no responde a la medicación dopaminérgica habría que realizar pruebas de imagen de la articulación.

En el caso de dolor neurálgico, o si tiene características de polineuropatía, habría que solicitar un EMG si el dolor no cede con medicación dopaminérgica. Si el dolor tiene características de dolor talámico estaría indicado solicitar una RMN cerebral.

La solicitud de pruebas complementarias en pacientes con dolor y EP debería ser excepcional si el paciente mejora claramente con la medicación dopaminérgica. 
Para un abordaje sistemático del diagnóstico sugerimos consultar la Tabla IV.

Quinn y cols. (64) clasificaron el dolor en la EP en cuatro categorías:

1. Dolor que precede al diagnóstico de la EP.

2. Dolor del periodo "off".

3. Espasmos distónicos dolorosos.

4. Dolor de pico de dosis.

Para otros autores, los síndromes dolorosos y molestos en el párkinson por lo general surgen de estas cinco causas, siguiendo la clasificación propuesta por Ford $(65,66)$, quien se basó en los estudios de Goetz y Quinn $(64,67)$ y que implica la etiología del dolor y su asociación con los síntomas motores (Tabla II):

1. Dolor musculoesquelético relacionado con la mala postura, la inadecuada función mecánica o el desgaste físico.

2. Dolor radicular, por lo general relacionado con la artritis en el cuello o la espalda.

3. Dolor por distonía, torsión constante de un grupo de músculos o parte del cuerpo en una postura forzada.

4. Dolor acatísico debido a la inquietud extrema.

5. Un raro síndrome doloroso conocido como dolor "primario" o "central" que surge del cerebro.

\section{Dolor musculoesquelético}

Es el tipo de dolor más común y fácilmente identificable [36]. Las articulaciones y los músculos adoloridos son particularmente comunes en la EP. La rigidez, la falta de movimiento espontáneo, las anormalidades en la postura y las tensiones mecánicas inadecuadas en la marcha contribuyen al dolor musculoesquelético [68).

Con la inmovilidad prolongada de una de las extremidades pueden, ocasionalmente, desarrollarse bandas, por lo general en las manos o los pies; un ejemplo es la contractura de la mano en puño, que puede ocurrir tras una flexión prolongada de los dedos.

Una de las quejas musculoesqueléticas más comunes es la rigidez en los hombros, asociado con la intensidad de la acinesia, Ilegando a evolucionar algunas veces al llamado "hombro congelado" (este, de hecho, puede ser el primer signo de la EP) (69), relacionado a su vez con el incremento de la inactividad muscular. La prevalencia del dolor de hombro es estimada entre un 11 al $80 \%$, mientras que el hombro congelado en un 2 a un $8 \%$ de los pacientes con EP $[70,71)$.

En orden de prevenir los problemas de hombro, una evaluación de los rangos de movimiento sumado a una

TABLA IV

DIAGNÓSTICO DEL DOLOR EN LA ENFERMEDAD DE PARKINSON

Diagnóstico del dolor en la enfermedad de Parkinson

Detectar si existe dolor en el paciente con EP:

- Preguntar directamente al paciente si presenta dolor

- Preguntar directamente al paciente si refiere síntomas sensitivos (entumecimiento, color, frialdad, acorchamiento, etc.)

- Utilizar el Brief Pain inventory (BPI)

- Utilizar el cuestionario Medical Outcomes Study 36-item form (SF-36)

Clasificar el dolor (hacer diario on-off y de síntomas no motores):

a. Dolor asociado a la EP:

- Más intenso en el lado más sintomático de la EP

- Mejoría con el tratamiento dopaminérgico

a1. Dolor del periodo off

a2. Dolor distónico (espasmos distónicos dolorosos)

a3. Dolor de pico de dosis (asociado a discinesias)

b. Dolor no claramente asociado de forma directa a la EP (esperable una mejoría más leve con el

tratamiento dopaminérgico):

b1. Dolor radicular neuropático

b2. Dolor musculoesquelético

Exploración general y neurológica siempre que el paciente refiera dolor, para descartar cualquier otra posible causa de este, además de su EP

Exploraciones complementarias en casos seleccionados:

- Resonancia magnética lumbosacra si se sospecha radiculopatía

- Resonancia magnética cerebral si se sospecha síndrome talámico (p. ej.: origen brusco, descartar causa vascular]

- Electromiografía si se sospecha polineuropatía, radiculopatía, etc.

- Radiografía (dolor articular), etc.

Fuente: Santos García D, Aneiros Días A, Macias Arribi M, Llaneza González MA, Abella-Corral J, Santos-Canelles H. Síntomas sensoriales en la enfermedad de Parkinson. Rev Neurol 2010;50(Supl 2): S65-S74. DOI: 10.33588/rn.50S02.2009742. 
cuidadosa historia del dolor de hombro es crítico para proveer diagnóstico temprano y tratamiento (72).

Ocasionalmente puede ser desafiante distinguir entre el dolor de espalda debido a la EP y el causado por la artritis o la escoliosis. A veces, se requieren de otras pruebas tales como radiografías, ecografías y exámenes reumatológicos u ortopédicos.

Gundogdu y cols. (72) revelan que el 58,9 \% de los pacientes con EP tienen dolor musculoesquelético, el cual fue significativamente mayor al compararse con el grupo control, esto es, compatible con estudios previos en los cuales el dolor musculoesquelético estuvo en un rango del 30-70 \% en pacientes con EP $(73,74)$. Esta manifestación se incrementa con la edad, afectando a dos tercios de los pacientes con EP y con mayor prevalencia a las mujeres [75-77). El problema musculoesquelético más común fue el dolor de espalda baja $[46,4 \%)$, concordando con otros estudios $[78,79)$.

La camptocormia en EP es una enfermedad de afectación muscular poco frecuente, de aparición tardía (80). Su sintomatología consiste básicamente en lumbalgia crónica asociada a una cifosis secundaria a debilidad de la musculatura paravertebral lumbar. La cifosis se incrementa con la fatiga (81), es reductible completamente en decúbito supino (82-84) y presenta una relación mujer / hombre de 4/1. En un $20 \%$ de los casos se asocia a un déficit moderado de la musculatura escapular o pelviana.

El síndrome de Pisa es una forma de síndrome distónico raramente descrito en la EP y está asociado con el desbalance dopaminérgico-colinérgico estriatal. Primariamente fue descrito en pacientes que toman medicación neuroléptica y caracterizado por una flexión tónica lateral acompañada por una rotación del tronco en el plano sagital $(85,86)$.

El tratamiento adecuado para el dolor musculoesquelético en la EP depende de la causa del dolor. Si el dolor es el resultado de la excesiva inmovilidad o rigidez, el médico podría indicar terapia dopaminérgica, fisioterapia y un programa de ejercicios, que haga fuerte énfasis en el rango de movimiento, para prevenir el desarrollo de problemas musculoesqueléticos en el futuro. Los fármacos antinflamatorios y analgésicos no esteroideos pueden ayudar en las condiciones ortopédicas y reumatológicas.

\section{Dolor radicular y neuropático}

Este afecta desde el 5 al $14 \%$ de los pacientes con EP con dolor $(38,42,49)$, y está asociado con compresión focal asociada con enfermedad degenerativa de las articulaciones $(68,87)$.

La cifosis y la distonía, los cuales son características clínicas de la EP, pueden inducir estrés en la porción ventral del disco lumbar, lo que conlleva a herniaciones del disco lumbar y dolor radicular (88).

Se requiere una cuidadosa evaluación neurológica para confirmar la ubicación del nervio o raíz nerviosa involucrada, y determinar así la causa del problema; pueden ser necesarias evaluaciones con electroneuromiografía y neuroimagen. El dolor radicular suele tratarse con éxito con programas de movilidad y analgésicos, por lo que rara vez requiere cirugía. Los tratamientos farmacológicos de primera línea para el dolor neuropático son amitriptilina, duloxetina y pregabalina (89).

\section{Dolor asociado con la distonía}

Los espasmos distónicos están entre los síntomas más dolorosos que una persona con EP puede experimentar. La distonía se define como una alteración neuroquímica-muscular del sistema nervioso central [SNC] que conduce a la aparición de contracciones musculares involuntarias que resultan en movimientos y/o posturas anormales dolorosas, sostenidas y repetitivas que pueden afectar distintas regiones (90).

Este tipo de espasmos musculares son muy diferentes de los movimientos repetitivos y oscilatorios descritos como discinecias, los cuales no son dolorosos. La distonía en la EP puede afectar las extremidades, el tronco, el cuello, la lengua, la mandíbula, los músculos deglutorios, las cuerdas vocales y las extremidades inferiores.

Es importante establecer si la distonía dolorosa tiene relación con la medicación dopaminérgica. ¿Se presenta la distonía cuando el medicamento está en su efecto máximo? ¿O se presenta como un fenómeno de "off" cuando empiezan a desvanecerse los efectos del medicamento al final de la dosis? Las respuestas a estas preguntas, por lo general, clarificarán la naturaleza y el momento de la distonía, y por tanto determinarán su tratamiento. La distonía más dolorosa se presenta cuando comienza la disminución de los niveles plasmáticos del medicamento y comúnmente se presenta temprano en la mañana [68].

En términos de tratamiento, la distonía del despertar suele aliviarse con la actividad física o con la primera dosis de la medicación dopaminérgica. Pocos pacientes experimentan espasmos distónicos como resultado de la medicación. La estrategia estándar de tratamiento para estos individuos es reducir la cantidad de dopamina, y algunas veces sustituirla por un agente menos potente, o agregar medicación para la distonía, como la amantadina.

Beiske y cols. encontraron que los pacientes con dolor distónico y central tras el tratamiento dopaminérgico presentaron mejor respuesta $[37$ y $40 \%$ de los casos) al compararlo con los pacientes que presentaban dolor músculoesquelético y radicular neuropático (17 y $14 \%$, respectivamente) [50).

Los individuos con una distonía intratable podrían beneficiarse de una estimulación cerebral profunda, un procedimiento neuroquirúrgico que involucra la implantación y activación de electrodos en el cerebro (68).

\section{Sindrome de dolor central}

Afecta desde el 4 al $10 \%$ de los pacientes con EP con dolor. Los mecanismos fisiopatológicos de este tipo de dolor en pacientes con EP no han sido bien establecidos [91). A pesar de que el dolor neuropático central en EP fue descrito inicialmente en 1921, por Souques (92) como un dolor parkinsoniano primario, se trata de un síntoma que ha sido poco estudiado y se ha sugerido que puede ser debida una disfunción del sistema nervioso central en el procesamiento nociceptivo $(68,93)$, como lo sugiere la disminución del umbral para el dolor producido por estímulos de calor en algunos de estos pacientes (94), así como la alteración en la modulación del dolor, por el déficit 
dopaminérgico en los circuitos ganglio basales-tálamocorticales [65].

El tratamiento del dolor central en la EP es desafiante, y por lo general comienza con la administración de agentes dopaminérgicos $(48,65,95)$. Adicionalmente, el tratamiento con opioides, antidepresivos, anticonvulsivantes y antipsicóticos pueden ser útiles en el tratamiento del dolor central.

\section{Acatisia}

La acatisia se define como una constante necesidad de moverse o cambiar de posición, la cual es una queja frecuente y potencialmente discapacitante, trayendo como consecuencia la pérdida del sueño o aislamiento social. Aunque a veces se describe como una sensación dolorosa, este no es normalmente el caso y no debe considerarse como una alteración sensorial (36).

En aproximadamente la mitad de los casos de acatisia parkinsoniana, los síntomas fluctúan con los medicamentos y suelen aliviarse con tratamiento dopaminérgico adicional (72). En caso de ser refractario al tratamiento, se plantea la conducta neuroquirúrgica (ver más adelante), así como estimulación cerebral profunda y/o palidotomía unilateral $(96,97)$.

Existen otros síndromes dolorosos que han sido descritos en estos pacientes

\section{Sindrome de piernas inquietas}

El síndrome de piernas inquietas (98) (SPI) es frecuente en los pacientes con EP, y puede llegar a ser doloroso en algunos casos. Se presenta fundamentalmente al final del día. Puede ser confundido con la acatisia. Mejora con la medicación dopaminérgica.

\section{Dolor abdominal}

Es frecuente y puede estar relacionado con el estreñimiento. El aumento en la dosificación de levodopa o de agonistas DA pueden empeorarlo. Otras veces, los pacientes en situación "off" refieren sensación de distensión abdominal con flatulencia acompañada de dolor, que mejora tras la administración de levodopa (99).

\section{CONTROL DEL DOLOR}

Teniendo en cuenta que existe un desequilibrio bioquímico en el que predomina la acetilcolina sobre la dopamina, la terapia farmacológica se basa en la administración de agentes anticolinérgicos, sustitutos de la dopamina, agonistas dopaminérgicos, bloqueadores de la degradación de dopamina y terapia coadyuvante $(1,9,100)$.

Los fenómenos sensitivos que ocurren en estados de hipofunción dopaminérgica podrían interpretarse como efecto directo de la desinhibición de las vías sensitivas desde los ganglios de la base $(64,101)$. Fil y cols. (102) establecen factores que afectan potencialmente al dolor en EP, a saber:

- Edad avanzada: el más prevalente es el dolor musculo esquelético.

- Sexo: Beiske y cols. (50) encontraron que la mujer añosa es un elemento predictor de dolor en EP.

- Depresión.

- Enfermedades preexistentes y trastornos sistémicos.

El dolor en la EP suele ser el resultado de una terapia dopaminérgica inadecuada (103). Las personas con EP que en el estado "on", cuando el medicamento está en la eficacia máxima, reportan menos dolor que aquellos en el estado "off" (Tabla V). El dolor debido a la distonía o a la rigidez se puede aliviar con medicamentos de dopamina, pero por otro lado, puede llevar al desarrollo

TABLA V

FÁRMACOS UTILIZADOS EN LA ENFERMEDAD DE PARKINSON

\begin{tabular}{|c|c|c|}
\hline $\begin{array}{l}\text { Fármacos que aumentan la } \\
\text { actividad dopaminérgica }\end{array}$ & Precursores de dopamina & $\begin{array}{l}\text { Levodopa (solo o asociada } \\
\text { a inhibidores de la dopa } \\
\text { descarboxilasa: benserazida o } \\
\text { carbidopa) }\end{array}$ \\
\hline & Agonistas dopaminérgicos & $\begin{array}{l}\text { Derivados ergóticos: bromocriptina, } \\
\text { lisurida, perfolida y cabergolina } \\
\text { Derivados no ergóticos: ropirinol, } \\
\text { pramipexol y apomorfina }\end{array}$ \\
\hline & $\begin{array}{l}\text { Inhibidores del metabolismo de la } \\
\text { dopamina }\end{array}$ & $\begin{array}{l}\text { Inhibidores de la MAO: selegilina y } \\
\text { rasagilina } \\
\text { Inhibidores de la COMT: } \\
\text { entacapona }\end{array}$ \\
\hline $\begin{array}{l}\text { Fármacos que disminuyen la } \\
\text { actividad colinérgica }\end{array}$ & Anticolinérgicos de acción central & $\begin{array}{l}\text { Trihexifenidil, biperideno y } \\
\text { prociclidina }\end{array}$ \\
\hline Amantadina & & \\
\hline
\end{tabular}

Fuente: Gómez Ayala A. Enfermedad de Parkinson abordaje terapéutico y farmacológico. Farmacoterapia 2007;26(5). 
de disquinesias. Por ello, la gestión eficaz de la medicación levodopa para los pacientes con EP puede ayudar a reducir el dolor.

Cuando el dolor es muy intenso y no conseguimos suprimirlo durante los periodos off, se podría intentar con inyecciones subcutáneas de apomorfina $(104,105)$. En caso de fluctuaciones que no se controlan con el tratamiento médico habitual se podría plantear la colocación de una bomba de apomorfina o una infusión continua de levodopa.

Si el dolor se asocia a una distonía "off" puede mejorar con inyecciones locales de toxina botulínica (106), aplicado a los músculos afectados por la distonía.

Técnicas como la terapia cognitiva-conductual (que ayuda a controlar la respuesta psicológica al dolor, la enseñanza de la respiración diafragmática, ejercicios de imágenes visuales, técnicas de relajación, etc.] y la biorretroalimentación también han demostrado su utilidad.

Dentro de algunos de estos caminos farmacológicos tenemos (18):

\section{Anticolinérgicos}

Los anticolinérgicos son útiles en las primeras etapas para el control de la rigidez y el temblor, mediante la restauración del equilibrio entre la actividad dopaminérgica y la acetilcolinérgica. Entre ellos están la prociclidina, la isotazina el trihexifenidil, el biperideno y la etopropaziana. Los efectos adversos incluyen midriasis, boca seca, estreñimiento, retención urinaria y efectos psiquiátricos como pérdida de la memoria y concentración, confusión y alucinaciones visuales. La suspensión brusca de estos podría causar la exacerbación del parkinsonismo y la precipitación de la crisis colinérgica.

\section{Sustitutos de la dopamina}

La levodopa es el medicamento más eficaz para el tratamiento de la EP. Dado que la dopamina no atraviesa la barrera hematoencefálica, se administra su precursor, la levodopa, que incrementa efectivamente la síntesis de dopamina en las neuronas remanentes del sistema nigroestriatal. Como la enzima descarboxilasa que transforma la levodopa en dopamina se encuentra presente a nivel central y periférico, la administración de levodopa debe acompañarse de un inhibidor de la dopa-descarboxilasa que no cruce la barrera hematoencefálica, como la carbidopa o la benserazida, con el fin de evitar metabolismo periférico de la levodopa. Esta

TABLA VI

TRATAMIENTO DEL DOLOR EN EP

\section{Tratamiento del dolor en la enfermedad de Parkinson}

Dolor asociado a la EP:

I) Terapia dopaminérgica:

la) Dolor del periodo "off": terapia dopaminérgica, fundamentalmente levodopa y agonistas dopaminérgicos

lb) Dolor distónico: terapia dopaminérgica

Ic) Dolor de pico de dosis (discinesias dolorosas): reducir tratamiento dopaminérgico

II) Asociar antidepresivos tricíclicos: si no hay mejoría

III) Asociar antiepilépticos: si no hay mejoría (gabapentina, pregabalina)

IV) Asociar opioides: si no hay mejoría

V) Toxina botulínica: en casos de distonía dolorosa grave

Dolor no claramente asociado de forma directa a la EP (mejoría esperable menor con tratamiento dopaminérgico):

I) Dolor radicular neuropático (tratamiento del dolor neuropático):

la) Primera línea: amitriptilina, gabapentina, pregabalina, carbamazepina

lb) Segunda línea: parche de lidocaína, oxcarbamacepina, duloxetina, metadona, venlafaxina

lc) Tercera línea: tramadol, opioides de liberación, antagonistas NMDA

Id) Cuarta línea: lamotrigina, topiramato

II) Dolor musculoesquelético:

Ila) No opioides: ácido acetilsalicílico, paracetamol, metamizol, AINE, coadyuvantes

Ilb) Opioides menores + no opioides + coadyuvantes

Ilc) Opioides mayores + no opioides + coadyuvantes

Ild) tratamientos intervencionistas

Considerar la cirugía en casos con dolor intenso y refractario

I) Coadyuvantes: antidepresivos, neurolépticos, antiepilépticos, corticoides

II) Opioides menores: codeína, tramadol, dextropropoxifeno

III) Opioides mayores: morfina, meperidina, fentanilo transdermico

Fuente: Santos García D, Aneiros Días A, Macias Arribi M, Llaneza González MA, Abella-Corral J, Santos-Canelles H. Síntomas sensoriales en la enfermedad de Parkinson. Rev Neurol 2010;50(Supl 2): S65-S74. D0I: 10.33588/ rn.50502.2009742. 
inhibición terapéutica es importante para aumentar la disponibilidad de levodopa a nivel central y para disminuir los efectos periféricos no deseados, como la activación de la zona quimiorreceptora del área postrema, la cual se ubica por fuera de la barrera hematoencefálica y cuya activación por la dopamina causa emesis importante.

Se suele utilizar cuando los síntomas de parkinsonismo causan cierto grado de invalidez y, usualmente, se evita su uso al inicio de la enfermedad, ya que suele provocar discinesias y agrava otras como la hipotensión postural y los síntomas psiquiátricos. Adicionalmente, el paciente puede eventualmente desarrollar una respuesta fluctuante a la terapia, con periodos de relativo buen control de los síntomas e inicio súbito de los mismos. Esto se conoce como fenómeno on-off y puede llegar a ser realmente incapacitante dado lo impredecible de su aparición.

\section{Agonistas de los receptores dopaminérgicos}

Usualmente se utilizan cuando declina la respuesta al tratamiento con levodopa o cuando la misma causa efectos adversos. Entre ellos están la bromocriptina, el pergolide y el lisuride. Entre los efectos secundarios están la hipotensión, las náuseas, el vómito y las alucinaciones.

\section{Bloqueadores de la degradación de dopamina}

Otra opción es la utilización de medicamentos que bloqueen el metabolismo de la dopamina por parte de la monoaminooxidasa (MAO) como el selegiline (107).

\section{Inhibidores de la COMT}

Estos fármacos aumentan los valores cerebrales de levodopa al inhibir su metabolismo. Su uso, por tanto, está indicado en asociación con levodopa en pacientes con dopaterapia y fluctuaciones motoras. En este sentido, aumentan los periodos "on" y disminuyen los "off" en pacientes con estas fluctuaciones, en enfermedad leve a moderada.

El hecho de que aparentemente también mejore la función motora en pacientes sin fluctuaciones hace que algunos autores propongan su uso asociado a la levodopa desde el inicio del tratamiento, aunque este punto aún no está establecido con claridad. El uso de inhibidores de la COMT, sin embargo, puede aumentar el riesgo de discinesias.

\section{Medicación coadyuvante}

La amantadina es un agente antiviral cuyo mecanismo de acción no está completamente aclarado pero que, probablemente actúa facilitando la liberación de dopamina a nivel estriatal, bloqueando su recaptación y estimulando los receptores dopaminérgicos (9). El empleo de amantadina debería considerarse siempre antes de decidir el tratamiento quirúrgico de las disquinesias secundarias a la terapia crónica con L-dopa (108).
Además, se debe tener en cuenta la utilización de otros medicamentos para el control de síntomas no motores asociados a la EP (depresión, estreñimiento, psicosis, etc.). Entre ellos están los antidepresivos (antidepresivos tricíclicos, inhibidores de la recaptación de serotonina), los laxantes o enemas y los antipsicóticos como el clozapine y el quetiapine (109).

Si la respuesta al dolor es insuficiente, los antidepresivos tricíclicos podrían ser de utilidad (110), ya que tienen un efecto anticolinérgico; los inhibidores de la recaptación de serotonina exacerban el parkinsonismo en algunos pacientes (7). Otra medida sería intentar con fármacos antiepilépticos, como la gabapentina o la pregabalina, aunque no hay ningún estudio que lo avale.

\section{Cannabinoides}

Una mención especial merecen los cannabinoides, los cuales pueden actuar, con eficacia neuroprotectora, sobre algunos de los fenómenos comentados relacionados con el daño nigroestriado, lo que podría ser de utilidad para disminuir o enlentecer el curso de la enfermedad. Tanto cannabinoides exógenos como endógenos (que incluyen a los clásicos como anandamida y 2-araquidonilglicerol y a los análogos cannabinoides como la oleiletanolamida [OEA] y la palmitoiletanolamida [PEA]] poseen eficacia neuroprotectora. Los análogos cannabinoides actúan principalmente a través de receptores activados por proliferadores de peroxisomas (PPAR), que incluyen PPARalfa, PPARbeta y PPARgamma (111).

Ciertos cannabinoides, como el cannabidiol, delta9-THC, cannabinol, nabilona, etc., tienen capacidad de disminuir el estrés oxidativo (112). Estudios con modelos animales de párkinson así lo confirman, y sus efectos parecen ser debidos a propiedades antioxidantes per se, pues no actúan a través de los receptores cannabinoides CB1 o CB2 (113). En cultivos celulares de neuronas de dopamina de la sustancia negra el delta-9-THC también muestra actividad antioxidante contra el tóxico 6-OHDA, sin participar los receptores CB1. La OEA y la PEA también poseen propiedades antioxidantes, pues la acción agonista sobre PPAR disminuye el estrés oxidativo inducido por 6-OHDA (114), reduce la actividad de la enzima iNOS- sintetasa de óxido nítrico, de gran importancia oxidativa (115), e incrementa la actividad de las enzimas antioxidantes cerebrales (116). Estos análogos cannabinoides son candidatos muy interesantes como compuestos neuroprotectores, porque son producidos por las propias neuronas y la glía en respuesta al estrés oxidativo $(117,118)$. Diversos experimentos han puesto de manifiesto dicha eficacia, pero también un posible efecto "ventana" (solo ciertas dosis son efectivas] que podría limitar su uso. Este efecto se debe a que coactúan sobre el receptor TRPV1 y la activación de este receptor posee acciones deletéreas sobre neuronas dopaminérgicas $(119,120)$. Por eso se piensa que estos compuestos poseen actividad estimuladora PPAR y bloqueante TRPV1, lo que podrían ser de una mayor eficacia neuroprotectora.

Los agonistas cannabinoides poseen capacidad antiexcitóxica, disminuyendo la liberación de glutamato, a través de receptores CB1presinápticos $(121,122)$. 
Pueden ser eficaces en disminuir el exceso de actividad glutamatérgica procedente del núcleo subtalámico, centro hiperactivo en la EP, al igual que hacen otros fármacos como el riluzol, actualmente en ensayo clínico. Los agonistas cannabinoides CB1 también atesoran propiedades antinflamatorias, pues disminuyen los niveles de citocinas inflamatorias como TNF-alfa, IL12 o incrementan los niveles de IL-10, citocina antiinflamatoria (123). Los agonistas PPAR disminuyen la actividad de factores proinflamatorios como NFkB, AP-1 y NFAT.

En resumen, diversos cannabinoides muestran eficacia neuroprotectora sobre las neuronas de dopamina, a través de una acción antioxidante, antinflamatoria o antiexcitotóxica. La liberación endógena de cannabinoides tras daño neuronal constituye una respuesta fisiológica protectora.

En casos extremos, y con ausencia o escasa respuesta a la terapia farmacológica, se valoraría la posibilidad del tratamiento quirúrgico (124). Entre estas opciones quirúrgicas están las siguientes:

- Palidotomía: lesiona el globo pálido en su porción interna y el ansa lenticularis, lo que alivia la excesiva inhibición talámica y mejora síntomas como la rigidez y la bradicinesia.

- Talidotomía: mejora el temblor.

- Estimulación subtalámica profunda: mediante la implantación de electrodos puede dirigirse al globo pálido o a los núcleos subtalámicos, lográndose mejoría del temblor en el hemicuerpo contralateral (125,126).

- Implantación de células fetales en la substancia nigra: mejora considerablemente los síntomas mediante el crecimiento y formación de nuevas sinapsis en el tejido trasplantado.

\section{CONCLUSIONES}

En los últimos años, los SNM en la EP han recibido una creciente atención de médicos e investigadores. El dolor está presente en las etapas preclínica e inicial de la enfermedad y es una causa de sufrimiento y de incapacidad en los pacientes con EP, causando un gran impacto en la calidad de vida y lamentablemente, con mucha frecuencia, pasa desapercibido en la práctica clínica porque habitualmente se presta la mayor atención a las alteraciones motrices. La prevalencia del dolor en pacientes con EP varía entre el 34 y el $83 \%$. Se ha descrito que en los estadios precoces de la enfermedad hay dolor de espalda y cuello, que puede resultar de la rigidez en la cintura escapular, y dolor en las piernas que puede ser producto del síndrome de las piernas inquietas o de distonías. En los estadios avanzados, el dolor puede ser causado por discinesia, acatisia, distonía del periodo "off" (40\%) y el dolor no distónico de tipo músculo esquelético, articular o radicular (20\%), como bien lo describió James Parkinson en su artículo original sobre la "parálisis agitante". En general, el dolor en la EP suele ser el resultado de una terapia dopaminérgica inadecuada, mejorando si se consigue una estimulación más continua de los receptores dopaminérgicos con levodopa, añadiendo inhibidores de la COMT o con agonistas dopaminérgicos. Aunque el dolor en la EP es generalizado e incapacitante en algunos casos, sus características clínicas y fisiopatológicas no se han definido del todo. Se necesitan más estudios para aclarar estos puntos y elucidar el papel de las vías dopaminérgicas y no dopaminérgicas en la nocicepción, la modulación central del dolor y las dimensiones afectivas/motivacionales en la percepción del dolor.

\section{BIBLIOGRAFÍA}

1. Gilman S. Parkinsonian syndromes. Clin Geriatr Med. 2006;22(4):827-42.

2. Benito-León J, Porta-Etessam J, Bermejo F. Epidemiología de la enfermedad de Parkinson. Neurología. 1998;13(Suppl.1):2-7.

3. Parkinson J. An essay on the shaking palsy. London: Whittingham \& Rowland; 1817

4. Schapira AHV. Science, medicine, and the future: Parkinson's disease. BMJ. 1999;318(7179):311-4.

5. Shannon K. Movement disorders in neurology in clinical practice. 4th edition. Bradley W, Daroff R, et al. Philadelphia Elsevier; 2004. p. 2125-65.

6. Chacón J, Dinca-Avarvarei L, Acosta J, Pastor-Cruz M, Burguera-Hernández J, Calopa-Garriga M, et al. Parkinson de inicio precoz. Rev Neurol. 2007;45(6):323-7. DOI: 10.33588/rn.4506.2007207

7. Rao S, Hofmann L, Shakil A. Parkinson's disease: diagnosis and treatment. Am Fam Physician. 2006;74(12):2046-54.

8. Forman MS, Trojanowski JQ, Lee VM. Neurodegenerative diseases: a decade of discoveries paves the way for therapeutic breakthroughs. Nat Med. 2004;10(10):1055-63. DOI: $10.1038 / \mathrm{nm} 1113$.

9. Albin RL. Parkinson's disease: background, diagnosis, and initial management. Clin Geriatr Med. 2006;22(4):735-51. DOI: 10.1016/j.cger.2006.06.003.

10. Kumar $\vee$ Robbins and Cotran Pathologic basis of disease. 7th edition. Philadelphia, Pennsylvania: Elsevier Saunders; 2005. p: 1385-97.

11. Morgado $\mathrm{H}$, Alonso M, López M. Factores genéticos involucrados en la susceptibilidad para desarrollar enfermedad de Parkinson. Salud Mental. 2007;30:16-24.

12. Jankovic J, Lang A. Movement disorders: diagnosis and assessment. Bradley W, Daroff R, et al. Neurology in Clinical Practice. 4th edition. Philadelphia: Elsevier; 2004. p. 294318.

13. Stella F, Bucken-Gobbi LT, Gobbi S, Sant'Ana-Simões C. Síntomas depresivos y trastorno motor en pacientes con enfermedad de Parkinson. Rev Neurol 2007;45(10):594-8.

14. Pont-Sunyer C, Hotter A, Gaig C, Seppi K, Compta Y, Katzenschlager $\mathrm{R}$, et al. The onset of nonmotor symptoms in parkinson's disease (the ONSET PD study). Mov Disord 2015;30(2):229-37. DOI: 10.1002/mds.26077.

15. Barone P, Antonini A, Colosimo C, Marconi R, Morgante L, Avarello TP, et al. The PRIAMO study: a multicenter assessment of nonmotor symptoms and their impact on quality of life in Parkinson's disease. Mov Disord. 2009;24(11):1641-9. DOI: 10.1002/mds.22643.

16. Baig F, Lawton M, Rolinski M, Ruffmann C, Nithi K, Evetts SG, et al., Delineating nonmotor symptoms in early Parkinson's disease and first-degree relatives Mov Disord. 2015;30(13):175966. DOI: 10.1002/mds.26281.

17. Charcot JM. Lectures on diseases of the nervous system. Translated by Sigerson G. London: The New Sydenham Society; 1877; 1: 137 
18. Arango M, Molina R. Consideraciones Anestésicas de la Enfermedad de Parkinson. Rev Col Anest. 2008. 36: 207215.

19. Abercrombie EY, DeBoer P. Substantia nigra D1 receptors and stimulation of striatal cholinergic interneurons by dopamine: a propose circuit mechanism. J Neurosci 1997; 17:8498-505.

20. Aizman O, Brismar H, Uhlen P, Zettergen E, Levey Al, Forssberg $\mathrm{H}$, et al. Anatomical and physiological evidence for D1 and D2 dopamine receptor colocalization in neostriatal neurons. Nat Neurosci 2000;3(3):226-30.

21. Sociedad Española de Investigación sobre Cannabinoides [SEIC]. Actualización sobre el Potencial Terapéutico de los Cannabinoides; 2009.

22. Wichmann T, DeLong MR. Pathophysiology of parkinsonian motor abnormalities. Adv Neurol. 1993;60:53-61.

23. Baba M, Nakajo S, Tu Ph, Nakaya K, Lee VM, Trojanowski JQ, et al. Aggregation of alpha-synuclein in Lewy bodies of sporadic Parkinson's disease and dementia with Lewy bodies. Am J Pathol 1998;152(4):879-84.

24. Spillantini MG, Schmidt ML, Lee VM, Trojanowski JQ, Jakes R, Goedert M. Alpha synuclein in Lewy bodies. Nature 1997;388(6645):839-40. DOl: 10.1038/42166.

25. Minguez Minguez S. Enfermedad de Parkinson, estudio sobre la adherencia al tratamiento, calidad de vida y uso del metanálisis para la evaluación de fármacos. Tesis Doctoral Universidad Castilla-La Mancha; 2013.

26. Fernández-Espejo E. Pathogenesis of Parkinson's disease prospects of neuroprotective and restorative therapies. Mo Neurobiol 2004;29(1):15-30. DOI: 10.1385/MN:29:1:15.

27. Sofic E, Riederer P, Heinsen H, Beckman H, Reynolds GP, Hebenstreit G, et al. Increased iron (III) and total iron content in postmortem substantia nigra of parkinsonian brain. J Neural Trans 1988;74(3):199-205.

28. Morris CM, Edwardson JA. Iron histochemistry of the substantia nigra in Parkinson's disease. Neurodegeneration 1994;3(4):277-82.

29. Shapira AHV, Cooper JM, Dexter D. Mithocondrial complex I deficiency in Parkinson's disease. Lancet 1989;1(8649):1269.

30. Hunot S, Boissiere F, Faucheux B, Brugg B, MouattPrigent $A$, Agid $Y$, et al. Nitric oxide synthase and neuronal vulnerability in Parkinson's disease. Neuroscience 1996; 72(2):355-63.

31. Floor $\mathrm{E}$, Wetzel MG. Increased protein oxidation in human substantia nigra pars compacta in comparison with basal ganglia and prefrontal cortex measured with an improved dinitrophenylhydrazine assay. J Neurochem 1998;70(1):2682-75.

32. Dexter DT, Carter CJ, Wells FR, Javoy-Agid F, Agid $Y$, Lees $A$, et al. Basal lipid peroxidation in substantia nigra is increased in Parkinson's disease. J Neurochem 1989;52(2):381-9.

33. Alam ZI, Zenner A, Daniel SA, Lees AJ, Caims N, Marsdem $C D$, et al. Oxidative DNA damage in the parkinsonian brain: an apparent selective increase in 8-hydroxyguanine levels in substantia nigra. J Neurochem 1997;69(3):1196-203.

34. Garcia-Ruiz PJ, Chaudhuri KR, Martinez-Martin P. Non-motor symptoms of Parkinson's disease: a review...from the past. J Neurol Sci. 2014 15;338(1-2):30-3. DOI: 10.1016/j. jns.2014.01.002.

35. Lin $\mathrm{CH}$, Wu RM, Chang HY, Chiang $\mathrm{YT}$, Lin HH, Preceding pain symptoms and Parkinson's disease: a nationwide population-based cohort study. Eur J Neurol. 2013;20(10):1398404. DOl: 10.1111/ene.12197.
36. Kim YE, Jeon BS. Musculoskeletal problems in Parkinson's disease. J Neural Transm (Vienna). 2013;120(4):537-42. DOI: 10.1007/s00702-012-0960-2.

37. Roh JH, Kim BJ, Jang JH, Seo WK, Lee SH, Kim JH, et al. The relationship of pain and health-related quality of life in Korean patients with Parkinson's disease. Acta Neurol Scand. 2009 Jun;119(6):397-403. DOI: 10.1111/j.16000404.2008.01114.x

38. Beiske AG, Loge JH, Rønningen A, Svensson E. Pain in Parkinson's disease: prevalence and characteristics. Pain. 2009;141(1-2):173-7. DOI: 10.1016/j. pain.2008.12.004..

39. Defazio G, Berardelli A, Fabbrini G, Martino D, Fincati E, Fiaschi A, et al., Pain as a nonmotor symptom of Parkinson disease: evidence from a case-control study. Arch Neurol. 2008;65(9):1191-4. DOI: 10.1001/archneurol.2008.2.

40. Nègre-Pagès L, Regragui W, Bouhassira D, Grandjean H, Rascol O. Chronic pain in Parkinson's disease: the cross-sectional French DoPaMiP survey. Mov Disord. 2008;23(10):1361-9. DOI: $10.1002 / \mathrm{mds} .22142$

41. Rana $A Q$, Kabir A, Jesudasan M, Siddiqui I, Khondker S. Pain in Parkinson's disease: analysis and literature review. Clin Neurol Neurosurg. 2013;115(11):2313-7. DOI: 10.1016/j.clineuro.2013.08.022.

42. Ha AD, Jankovic J. Pain in Parkinson's disease. Mov Disord. 2012;27(4):485-91. DOI: 10.1002/mds.23959.

43. Tinazzi M, Del Vesco C, Fincati E, Ottaviani S, Smania N, Moretto G, et al. Pain and motor complications in Parkinson's disease. J Neurol Neurosurg Psychiatry. 2006;77(7):822-5.

44. Wasner G, Deuschl G. Pains in Parkinson diseasemany syndromes under one umbrella. Nat Rev Neurol. 2012;8(5):284-94. DOI: 10.1038/nrneurol.2012.54.

45. Ehrt U, Larsen JP, Aarsland D. Pain and its relationship to depression in Parkinson disease. Am J Geriatr Psychiatry. 2009; 17(4):269-75.

46. Defazio G, Gigante A, Mancino P, Tinazzi M. The epidemiology of pain in Parkinson's disease. J Neural Transm (Vienna). 2013;120(4):583-6. DOI: 10.1007/s00702-0120915-7.

47. Zhang LM, Chen YQ, Li WJ, Sun W, Huang Y, Zou HQ. Association between mutations of SCN9A gene and pain related to Parkinsonism. Zhonghua Yi Xue Yi Chuan Xue Za Zhi. 2013;30(1):17-20. DOl: 10.3760/cma.j.is sn.1003-9406.2013.01.005.

48. Santos Garcia D, Aneiros Días A, Macias Arribi M, Llaneza González MA, Abella-Corral J, Santos-Canelles H. Síntomas sensoriales en la enfermedad de Parkinson. Rev Neurol 2010;50(Supl 2): S65-S74. DOI: 10.33588/ rn.50502.2009742.

49. Lee $M$, Walker R, Hildreth $T$, et al. A survey of pain in idiopathic Parkinson's disease. J Pain Symptom Manage 2006;32(5):462-9.

50. Ford B, Louis ED, Greene P, Fahn S. Oral and genital pain syndromes in Parkinson's disease. Movement Disorders 1996;11(4):421-26. DOI: 10.1002/mds.870110411.

51. Lee MA, Walker RW, Hildreth TJ, Prentice WM. A survey of pain in idiopathic Parkinson's disease. J Pain Symptom Manage. 2006 Nov;32(5):462-9.

52. Rana $A Q$, Saeed U, Masroor MS, Yousuf MS, Siddiqui I. A cross-sectional study investigating clinical predictors and physical experiences of pain in Parkinson's disease. Funct Neurol. 2013;28(4):297-304. DOI: 10.11138/ FNeur/2013.28.4.297. 
53. Lin XJ, Yu N, Lin XG, Zhang YF, Chen Y, Zhang K, et al. A clinical survey of pain in Parkinson's disease in Eastern China. Int Psychogeriatr. 2016;28(2):283-9. DOI: 10.1017/ S1041610215001659.

54. Valkovic P, Minar M, Singliarova H, Harsany J, Hanakova M, Martinkova J, et al. Pain in Parkinson's disease: a cross-sectional study of its prevalence, types, and relationship to depression and quality of life. PLoS One. 2015;10(8):e0136541. DOI: 10.1371/journal.pone.0136541.

55. Hanagasi HA, Akat S, Gurvit H, Yazici J, Emre M. Pain is common in Parkinson's disease. Clin Neurol Neurosurg. 2011;113(1):11-3. DOI: 10.1016/j.clineuro.2010.07.024.

56. Skogar Ö, Fall PA, Hallgren G, Bringer B, Carlsson M, Lennartsson $U$, et al. Parkinson's disease patients' subjective descriptions of characteristics of chronic pain, sleeping patterns and health-related quality of life. Neuropsychiatr Dis Treat. 2012;8:435-42. DOI: 10.2147/NDT.S34882.

57. Quittenbaum B, Grahn B. Quality of life and pain in Parkinson's disease: A controlled cross-sectional study. Parkinsonism Relat Disord. 2004;10(3):129-36. DOI: 10.1016/j.parkreldis.2003.12.001.

58. Letro GH, Quagliato EM, Viana MA. Pain in Parkinson's Disease. Arq. Neuro-Psiquiatr [online]. 2009;67(3a):585-90. DOI: 10.1590/S0004-282X2009000400003.

59. De Sales Coriolano MD, De Siqueira Balbino JM, Da Silva BR Dantas Cabral E, Guescel Asano A, Gome Lins O, et al. Pain characterization in patients with Parkinson's disease. Revista Dor 2014;15(2):78-82. DOI: 10.5935/1806-0013.20140019.

60. Nebe A, Ebersbach G. Pain intensity on and off Levodopa in patients with Parkinson's disease. Mov Disord. 2009;24(8):1233-7. D0I: 10.1002/mds.22546.

61. Chaudhuri KR, Rizos A, Trenkwalder C, Rascol O, Pal S, Martino D, et al. King's Parkinson's disease pain scale, the first scale for pain in PD: an international validation. Mov Disord. 2015;30(12):1623-31. D0I: 10.1002/mds.26270.

62. Cersosimo M, Micheli F. Enfermedad de Parkinson. En: Micheli F, Fernandez Pardal M, Cersosimo M. Neurología en el anciano. $2^{a}$ ed. Editorial Panamericana; 2014. p. 209-41.

63. Tolosa E, Compta Y, Gaig C. The premotor phase of Parkinson's disease. Parkinsonism Relat Disord 2007;13(Suppl):52-57. DOI: 10.1016/j.parkreldis.2007.06.007.

64. Quinn NP, Koller WC, Lang AE, Marsden CD. Painful Parkinson's disease. Lancet 1986;1(8494):1366-9.

65. Ford B. Pain in Parkinson's disease. Clin Neurosci 1998;5(2):63-72.

66. Kulisevsky J, Luquin M, Arbelo J, Burguera JA, Carrillo F, Castro A, et al. Enfermedad de Parkinson avanzada. Características y tratamientos (Parte I). Neurología 2013;28(8):50321. DOI: 10.1016/j.nrl.2013.05.001

67. Goetz CG, Tanner CM, Levy M, Wilson RS, Garron DC. Pain in Parkinson's disease. Mov Disord. 1986;1(1):45-9.

68. Ford B. Pain in Parkinson's disease. Movement Disorders 2010;25(Suppl 1):S98-S103. DOI: 10.1002/mds.22716.

69. Stamey W, Davidson A, Jankovic J. Shoulder pain a presenting symptom of Parkinson disease. J Clin Rheumatol 2008;14(4):253-4. DOI: 10.1097/ RHU.Ob013e3181826d43.

70. Riley D, Lang AE, Blair RD, Birnbaum A, Reid B. Frozen shoulder and other shoulder disturbances in Parkinson's disease. J Neurol Neurosurg Psychiatry 1989;52(1):63-6. DOI: 10.1136/jnnp.52.1.63.

71. Madden MB, Hall DA. Shoulder pain in Parkinson's disease: a case-control study. Mov Disord. 2010;25(8):1105-6. DOI: $10.1002 /$ mds. 23048 .
72. Gundogdu I, Ozturk EA, Nazli F, Aypak C, Comoglu S, Cakci A. Musculoskeletal pain and deformities in Parkinson's disease. Int J Clin Exp Med 2016;9(7):14663-9.

73. Tinazzi M, Del Vesco C, Fincati E, Ottaviani S, Smania N, Moretto G, et al. Pain and motor complications in Parkinson's disease. J Neurol Neurosurg Psychiatry 2006;77(7):822-5.

74. Silva EG, Viana MA, Quagliato EM. Pain in Parkinson's disease: analysis of 50 cases in a clinic of movement disorders. Arq Neuropsi- quiatr 2008;66(1):26-9.

75. Woolf $A D$, Pfleger $B$. Burden of major musculoskeletal conditions. Bull World Health Organ 2003;81(9):646-56.

76. Kim YE, Lee WW, Yun JY, Yang HJ, Kim HJ, Jeon BS. Musculoskeletal problems in Parkin- son's disease: neglected issues. Parkinsonism Relat Disord 2013; 19(7):666-9. DOI: 10.1016/j.parkreldis.2013.03.002.

77. Kim YE, Jeon BS. Musculoskeletal problems in Parkinson's disease. J Neural Transm 2013;120(4):537-42. DOI: 10.1007/s00702-012-0960-2.

78. Broetz D, Eichner M, Gasser T, Weller M, Steinbach JP. Radicular and nonradicular back pain in Parkinson's disease: a controlled study. Mov Disord 2007;22(6):853-6. DOI: $10.1002 / \mathrm{mds} .21439$.

79. Sandyk R. Back pain as an early symptom of Parkinson's disease. S Afr Med J 1982; 61(1):3.

80. Laroche M, Delisle MB. La camptocormie primitive est une myopathie para-vertébrale. Rev Rhum (Ed Fr) 1994;61(78):481-4.

81. Laroche M, Delisle MB, Mazières B, Rascol A, Cantagrel A, Arlet $P$, et al. Myopathie tardive localisée aux muscle spinaux: une cause de cyphose lombaire acquise de l'adulte. Rev Rhum (Ed Fr) 1991;58: 829-38.

82. Ashour R, Tintner R, Jankovic J. Striatal deformities of the hand and foot in Parkinson's disease. Lancet Neurol 2005;4(7):42331. DOI: 10.1016/S1474-4422(05)70119-8.

83. Ashour R, Jankovic J. Joint and skeletal deformities in Parkinson's disease, multiple system atrophy, and progressive supranuclear palsy. Mov Disord 2006;21(11):1856-63. DOI: 10.1002/mds.21058.

84. Margraf NG, Wrede A, Rohr A, Schulz-Schaeffer WJ, Raethjen $\mathrm{J}$, Eymess A, et al. Camptocormia in idiopathic Parkinson's disease: a focal myopathy of the paravertebral muscles. Mov Disord 2010;25(5):542-51. D0l: 10.1002/mds.22780.

85. Cannas A, Solla P, Floris G, Borghero G, Tacconi P, Spissu A. Reversible Pisa syndrome in Parkinson's disease during treatment with pergolide: a case report. Clin Neuropharmacol 2005;28(5):252.

86. Kim JS, Park JW, Chung SW, Kim YI, Kim HT, Lee KS. Pisa syndrome as a motor complication of Parkinson's disease. Parkinsonism Relat Disord 2007;13(2):126-8. DOI: 10.1016/j.parkreldis.2006.03.010.

87. Serratrice G, Michel B. Pain in Parkinson's disease patients. Revue du Rhumatisme (English Ed.) 1999;66(4):331-8.

88. Adams MA, Freeman BJ, Morrison HP, Nelson IW, Dolan P. Mechanical initiation of intervertebral disc degeneration. Spine (Phila Pa 1976) 2000;25(13):1625-36.

89. Attal N, Cruccu G, Baron R, Haanpää M, Hansson P, Jensen TS, et al. EFNS guidelines on the pharmacological treatment of neuropathic pain: 2010 revision. Eur J Neurol 2010;17(9):111323. DOI: 10.1111/j.1468-1331.2010.02999.x.

90. Camargo $\mathrm{CH}$, Teive HA. Evolução do conceito de distonía. Arquivos de Neuro-Psiquiatria 2014;72(7):559-61.

91. Goetz CG, Tanner CM, Levy M, Wilson RS, Garron DC. Pain In idiopathic Parkinson's disease. Mov Disord. 1986;1:45-9. DOI: 10.1002/mds.870010106. 
92. Souques MA. Des douleurs dans la paralysie agitante. Rev Neurol (Paris). 1921;37:629-33.

93. Poewe W. Non-motor Symptoms in Parkinson's disease. Eur J Neurol. 2008;15(Suppl. 1):14-20. DOI: 10.1111/j.14681331.2008.02056.x.

94. Djaldetti R, Shifrin A, Rogowski Z, Sprecher E, Melamed E, Yarnitsky D. Quantitative measurement of pain sensation in Patients with Parkinson disease. Neurology. 2004;62(12):2171-5.

95. Brefel Courbon C, Payoux P, Thalamas C, Ory F, Quelven I, Chollet F, et al. Effect of pain threshold in Parkinson's disease. A clinical and positron emission tomography study. Mov Disord 2005;20(12):1557-63. DOI: 10.1002/ mds.20629.

96. Honey C, Stoessl A, Tsui J, Schulzer M, Calne DB. Unilateral pallidotomy for reduction of Parkinson pain. J Neurosurg 1999;91(2): 198-201. DOl: 10.3171/jns.1999.91.2.0198.

97. Loher T, Burgunder J, Weber S, Sommerhalder R, Krauss JK. Effect of chronic pallidal deep brain stimulation on off period dystonia and sensory symptoms in advanced Parkinson's disease. J Neurol Neurosurg Psychiatry 2002;73(4):395-9. DOI: 10.1136/jnnp.73.4.395.

98. Poewe W, Hogl B. Akathisia, restless legs and periodic limb movements in sleep in Parkinson's disease. Neurology 2004;63(8 Supl. 3):S12-6.

99. Waseem S, Gwinn-Hardy K. Pain in Parkinson's disease. Common yet seldom recognized symptom is treatable. Postgrad Med J 2001;110(6):33-4.

100. Mason LJ, Cojocaru TT, Cole DJ. Surgical intervention and anesthetic management of the patient with Parkinson's disease. Int Anesthesiol Clin. 1996;34(4):133-50.

101. Chudler $E$, Dong W. The role of the basal ganglia in nociception and pain. Pain 1995;60(1):3-38.

102. Fil A, Cano de la Cuerda R, Muñoz Hellin E, Vela L, RamiroGonzález M, Fernández-de-Las-Peñas C. Pain in Parkinson disease: a review of the literature. Parkinsonism Relat Disord March 2013;19(3):285-94. DOI: 10.1016/j.parkreldis.2012.11.009.

103. Vela L. El dolor en la enfermedad de Parkinson. Revista Española de Trastornos del Movimiento. 2006;2:11-6.

104. Mason LJ, Cojocaru TT, Cole DJ. Surgical intervention and anesthetic management of the patient with Parkinson's disease. Int Anesthesiol Clin. 1996;34(4):133-50.

105. Factor SA, Brown DL, Molho ES. Subcutaneous apomorphine injections as a treatm1ent for intractable pain in Parkinson's disease. Mov Disorders 2000;15(1):167-9.

106. Pacchetti C, Albani G, Martignoni E, Godi L, Alfonsi E, Nappi G. "Off" painful dystonia in Parkinson's disease treated with botulinum toxin. Mov Disorders 1995;10(3):333-6. DOI: 10.1002/mds.870100317.

107. Jankovic J. Parkinson's disease therapy of early and late disease. Chin Med J. 2001;114(3):227-34.

108. Cersosimo MG, Scorticati MC, Micheli FE. Amantadina en el tratamiento de las Diskinesias inducidas por Levodopa en la Enfermedad de Parkinson. Medicina (Buenos Aires) 2000;60:321-5.

109. Miyasaki JM, Shannon K, Voon V, Ravina B, Kleiner-Fisman $G$, Anderson $K$, et al. Practice parameter: evaluation and treatment of depression, psychosis and dementia in Parkinson's disease (an evidence based review). Am Acad Neurol. 2006. Consultado en marzo 2008 Disponible: http:/ /www.aan.com/ professionals/practice/guidelines/pda/eval_dementia_pd.pdf

110. Sandyk R. Anticholinergic-induced analgesia: possible role for the cholinergic system in abnormal sensory symptoms in Parkinson's disease. Postgrad Med J 1986;62(730):749-51.
111. Rodríguez de Fonseca F, Navarro M, Gómez R, Escuredo L, Nava F, Fu J, et al. An anorexic lipid mediator regulated by feeding. Nature 2001;414(6860):209-12.

112. Marsicano G, Moosmann B, Hermann H, Lutz B, Behl C. Neuroprotective properties of cannabinoids against oxidative stress: role of the cannabinoid receptor CB1. J Neurochem 2002;80(3):448-56.

113. Lastres-Becker I, Molina-Holgado F, Ramos JA, Mechoulam R, Fernández-Ruiz J. Cannabinoids provide neuroprotection against 6-hydroxydopamine toxicity in vivo and in vitro: relevance to Parkinson's disease. Neurobiol Dis. 2005;19(12):96-107. DOl: 10.1016/j.nbd.2004.11.009.

114. Beltowski J, Wojcicka G, Mydlarczyk M, Jamroz A. The effect of peroxisome proliferator-activated receptors alpha (PPARalpha) agonist, fenofibrate, on lipid peroxidation, total antioxidant capacity, and plasma paraoxonase 1 (PON 1) activity. J Physiol Pharmacol 2002;53(3):463-75.

115. Jellinger $K$, Linert $L$, Kienzl $E$, Herlinger $E$, Youdim MBH. Chemical evidence for 6-hydroxydopamine to be an endogenous toxic factor in the pathogenesis of Parkinson's disease. J Neural Transm 1995;46:297-314.

116. Deplanque D, Gele P, Petrault O, Six I, Furman C, Bouly M, et al. Peroxisome proliferator-activated receptor-alpha activation as a mechanism of preventive neuroprotection induced by chronic fenofibrate treatment. J Neurosci 2003;23:6264-71.

117. Berdyshev EV, Schmid PC, Dong Z, Schmid HH. Stressinduced generation of $\mathrm{N}$-acylethanolamines in mouse epidermal JB6 P+ cells. Biochem J 2000;346:369-74.

118. Schabitz WR, Giuffrida A, Berger C, Aschoff A, Schwaninger M, Schwab S, et al. Release of fatty acid amides in a patient with hemispheric stroke: a microdialysis study. Stroke 2002;33(8):2112-4.

119. Kim SR, Lee DY, Chung ES, Oh UT, Kim SU, Jin BK. Transient receptor potential vanilloid subtype 1 mediates cell death of mesencephalic dopaminergic neurons in vivo and in vitro. $J$ Neurosci 2005;25(3):662-71. DOI: 10.1523/JNEUROSCl.4166-04.2005.

120. Marinelli S, Di Marzo V, Florenzano F, Fezza F, Viscomi MT, van der Stelt M, et al. N-Arachidonoyl-dopamine tunes synaptic transmission onto dopaminergic neurons by activating both cannabinoid and vanilloid receptors. Neuropsychopharmacol. 2006;32(2):298308. DOI: 10.1038/sj.npp.1301118.

121. Grundy RI, Rabuffetti M, Beltramo M. Cannabinoids and neuroprotection . Mol Neurobiol 2001;24(1-3):29-51. DOl: 10.1385/MN:24:1-3:029

122. Van der Stelt M, Veldhuis WB, van Haaften GW, Fezza F, Bisogno T, Bar PR, et al. Exogenous anandamide protects rat brain against acute neuronal injury in vivo. J Neurosci 2001;21(22):8765-71.

123. Smith SR, Terminelli C, Denhardt G. Effects of cannabinoid receptor agonist and antagonist ligands on production of inflammatory cytokines and anti-inflammatory interleukin-10 in endotoxemic mice. J Pharmacol Exp Ther 2000;293:136-50.

124.Espay AJ, Mandybur GT, Revilla FJ. Surgical treatment of movement disorders. Clin Geriatr Med. 2006;22(4):813-25.

125. Honey CR, Stoessl AJ, Tsui JK, Schulzer M, Calne DB. Unilateral pallidotomy for reduction of parkinsonian pain. J Neurosurg 1999;91(2):198-201. DOI: 10.3171/ jns.1999.91.2.0198.

126. Loher TJ, Burgunder JM, Weber S, Sommerhalder R, Krauss JK. Effect of chronic pallidal deep brain stimulation on off period dystonia and sensory symptoms in advanced Parkinson's disease. J Neurol Neurosurg Psychiatry 2002;73(4):395-9. DOI: 10.1136/jnnp.73.4.395. 